\title{
Behavioral Detectability of Single-Cell Stimulation in the Ventral Posterior Medial Nucleus of the Thalamus
}

\author{
Birgit C. Voigt, ${ }^{1,2}$ Michael Brecht, ${ }^{1,2}$ and Arthur R. Houweling ${ }^{1,2}$ \\ ${ }^{1}$ Bernstein Center for Computational Neuroscience, Humboldt University, 10115 Berlin, Germany, and ${ }^{2}$ Erasmus Medical Center, Department of \\ Neuroscience, 3000 CA Rotterdam, The Netherlands
}

In mammals, most sensory information passes through the thalamus before reaching cortex. In the rat whisker system, each macrovibrissa is represented by $\sim 250$ neurons in the ventral posterior medial nucleus (VPM) of the thalamus and $\sim 10,000$ neurons in a cortical barrel column. Here we quantify the sensory impact of individual thalamic neurons in the rat VPM. We first trained animals to report microstimulation of VPM. All animals learned to report microstimulation currents of $2-5 \mu$ A. We then evoked action potentials (APs) in single thalamic neurons close to the microstimulation site using juxtacellular stimulation, adding on average 17.8 APs to 2.6 spontaneous APs during $200 \mathrm{~ms}$ current applications. A population analysis revealed that animals responded equally often in single-cell stimulation trials as in catch trials without stimulation, suggesting that APs of single thalamic cells in VPM lead to either no or only a very weak perceptual effect. These results are surprising given the relatively small number of VPM neurons and our previous observations that single neurons in other parts of the vibrissal system do have an impact on perception or motor output. Our findings therefore suggest that neural representations in whisker thalamus are more distributed than in other whisker-related structures.

Key words: thalamus; microstimulation; reverse physiology; single-neuron stimulation; perception; sensation

\section{Introduction}

The relationship between neural activity and perception is a key topic in neuroscience. It has been intensely investigated to what extent sensory processing is localized to brain areas and specific neural circuits. Electrical recordings have shown that large groups of neurons distributed across areas are associated with sensory detection (de Lafuente and Romo, 2006). At the same time, microstimulation experiments have established a direct link from local neural activity in cortex to perception of a sensory stimulus (Salzman et al., 1990; Romo et al., 1998; Afraz et al., 2006), suggesting that small neuronal populations can have an impact on sensory decision-making (Murasugi et al., 1993; Huber et al., 2008). Microstimulation, however, has the drawback that the number of activated cells is unknown (Tehovnik, 1996), as are their firing pattern and identity. Therefore, the sensory impact of individual neurons has remained unknown until recently. Using the juxtacellular stimulation technique, we showed that inducing $\sim 14$ action potentials (APs) in a single neuron in rat barrel somatosensory cortex can lead to a behavioral effect in a simple detection task (Houweling and Brecht, 2008).

In the present study, we extended this single-cell stimulation

\footnotetext{
Received July 1, 2008; revised Sept. 12, 2008; accepted Sept. 28, 2008.

This work was supported by Erasmus MC, the Bernstein Center for Computational Neuroscience, Humboldt University, the Ernst Schering Stiftung, Neurocure (M.B.), and the FP7 Biotact European Union Grant (M.B.). We thank J. van der Burg and E. Haasdijk for technical support, A. Lee for stimulating discussions, and all members of the Brecht laboratory for helpful comments on this manuscript.

Correspondence should be addressed to any of the following: Birgit C. Voigt, Michael Brecht, or Arthur R. Houweling, Bernstein Center for Computational Neuroscience, Humboldt University, Philippstrasse 13, Haus 6, 10115 Berlin, Germany.

E-mails: birgit.voigt@bccn-berlin.de, michael.brecht@bccn-berlin.de, arthur.houweling@bccn-berlin.de. DOI:10.1523/JNEUROSCI.3046-08.2008

Copyright $\odot 2008$ Society for Neuroscience $\quad$ 0270-6474/08/2812362-06\$15.00/0
}

approach to the ventral posterior medial nucleus (VPM), which is the main thalamic target of whisker input (Lund and Webster, 1967; Erzurumlu et al., 1980) arriving from the contralateral brainstem principal trigeminal nucleus (Ma, 1991). Individual whiskers are represented in VPM by anatomical structures called barreloids (Van der Loos, 1976). The 250-300 VPM cells that constitute a barreloid (Land et al., 1995) connect to 2500 layer 4 neurons of a barrel in the primary somatosensory cortex S1 (Woolsey and Van der Loos, 1970; Jones and Diamond, 1995; Bruno and Sakmann, 2006). VPM neurons respond more vigorously and reliably to whisker deflections than do barrel cortex neurons (Simons and Carvell, 1989; Brecht and Sakmann, 2002a,b), and their activity covaries with the behavioral state of the animal (Nicolelis and Fanselow, 2002; Castro-Alamancos, 2004).

Given these anatomical and physiological observations, one might expect that single VPM neurons exert a powerful sensory effect. Here we test this hypothesis by stimulating single thalamic neurons in the awake head-fixed rat and measuring its impact on detection behavior.

\section{Materials and Methods}

Experimental procedures. Male Wistar rats ( $n=9$; postnatal days 29-39 at the day of surgery) were handled and habituated to the experimental setup for 2-5 d before surgery. Animals were implanted under ketamine/ xylazine anesthesia (100 and $5 \mathrm{mg} / \mathrm{kg}$, i.p., respectively; supplementary injections of ketamine or ketamine/xylazine administered as needed) with a metal bolt for head fixation and a recording chamber (posterior, $3.0 \mathrm{~mm}$; lateral, $2.75 \mathrm{~mm}$ relative to bregma) for chronic access to VPM. Over several days, animals were habituated to head fixation and a water restriction schedule with access to water ad libitum for $1 \mathrm{~h} / \mathrm{d}$. Animals were then trained to report a $200 \mathrm{~ms}$ train of microstimulation pulses 
A

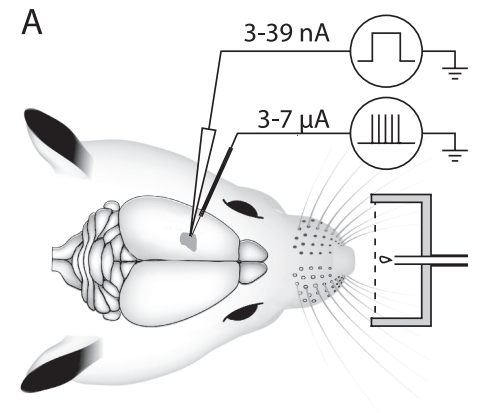

C juxtacellular recording

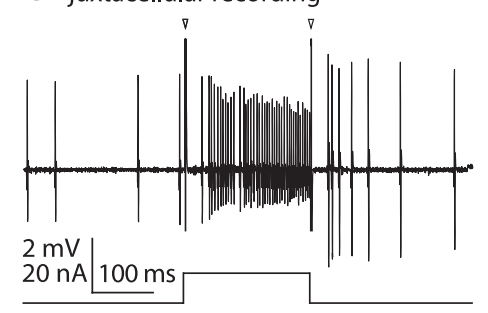

B
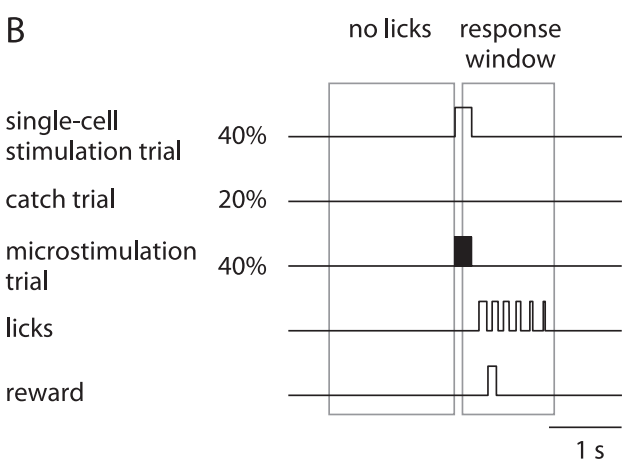

D

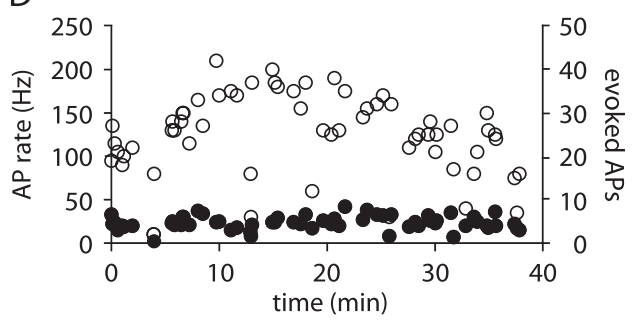

Figure 1. Juxtacellular single-cell stimulation in VPM thalamus. $A$, Behavioral setup. Awake head-fixed animals were trained to report electrical stimulation applied to VPM through a tungsten microelectrode. Animals were rewarded with a drop of sugar water if they interrupted a light beam (dashed line) by licking in response to stimulation. During single-cell stimulation experiments, a glass pipette was used to stimulate a single thalamic neuron close to the microstimulation site. $\boldsymbol{B}$, Single-cell stimulation detection task. Juxtacellular single-cell stimulation ( $40 \%$ probability), microstimulation (40\%), and catch trials without current injection (20\%) were presented in a random order (Poisson process; mean, $3 \mathrm{~s}$ ). If the first of usually multiple tongue licks occurred during the response window (0.1-1.2 s after stimulus onset), the animal was rewarded. Licks before stimulus presentation were mildly punished with an additional delay of $1.5 \mathrm{~s}$ to the next stimulus presentation. C, Single-cell stimulation trial. Top trace, Juxtacellular recording of APs. Arrowheads mark stimulation onset and offset artifacts. Bottom trace, Current injection waveform. D, Spontaneous (filled circles) and evoked (open circles) APs during a 38-min-long single-cell stimulation experiment. Spontaneous firing rates were quantified during a $1 \mathrm{~s}$ period before each stimulation. APs during $200 \mathrm{~ms}$ current injections are indicated as both a rate (left $y$-axis) and a number (right $y$-axis). This cell had a single-whisker receptive field corresponding to whisker C4 according to mapping with a hand-held probe.

applied to VPM (40 cathodal pulses at $200 \mathrm{~Hz}, 0.3 \mathrm{~ms}$ pulse duration) through a tungsten microelectrode and presented at random intervals (Fig. 1A). Tongue-lick responses were rewarded with a drop of sugar water and counted as a hit if they occurred within 100-1200 ms after stimulus onset. Results were similar if the response window was taken shorter $(0.5 \mathrm{~s})$ or longer $(2 \mathrm{~s})$. The time of the first lick after stimulus onset was taken as the reaction time.

Once animals performed at current intensities below $5 \mu \mathrm{A}$ on 2 consecutive days, we switched to single-cell stimulation experiments, as described previously (Houweling and Brecht, 2008). Briefly, during singlecell stimulation trials, a $200 \mathrm{~ms}$ square-wave current pulse was injected into a neuron through a glass pipette, and current strength was adjusted (range, 3-39 nA; median, $12 \mathrm{nA}$ ) to elicit a maximal number of APs without damaging the neuron. Single-cell stimulation trials, catch trials without current injection, and microstimulation trials were randomly interleaved and presented at random intervals (Poisson process; mean, $3 \mathrm{~s}$ ) (Fig. $1 \mathrm{~B}$ ). Microstimulation currents were adjusted (range, 3-7 $\mu \mathrm{A}$; mean $\pm \mathrm{SD}, 5.4 \pm 1.5 \mu \mathrm{A}$ ) such that animals performed close to the detection threshold, resulting in an average microstimulation hit rate of $87 \%$. To encourage animals to use a nonconservative response criterion, we only mildly punished licks in the interstimulus interval with an additional $1.5 \mathrm{~s}$ delay to the next stimulus presentation. The average interstimulus interval therefore depended on the frequency of interstimulus licks and measured $7.9 \pm 5.8 \mathrm{~s}$ over all recording sessions.

The glass pipette for juxtacellular single-cell stimulation and recording was glued to a tungsten microelectrode used for microstimulation with the tips separated by $57 \pm 18 \mu \mathrm{m}$. This distance is smaller than the diameter of a barreloid [ 75-275 $\mu \mathrm{m}$ (Haidarliu and Ahissar, 2001)]. It is therefore likely that, in many instances, both electrodes were situated in the same barreloid.
The pipette was filled with intracellular solution containing the following (in $\mathrm{mm}$ ): 135 K-gluconate, 10 HEPES, $10 \quad \mathrm{Na}_{2}{ }^{-}$ phosphocreatine, $4 \mathrm{KCl}, 4 \mathrm{MgATP}$, and 0.3 $\mathrm{Na}_{3} \mathrm{GTP}, \mathrm{pH}$ 7.2. The juxtacellular signal was amplified and low-pass filtered at $3 \mathrm{kHz}$ by a patch-clamp amplifier (Dagan) and sampled at 10 or $25 \mathrm{kHz}$ by a Power1401 data acquisition interface under the control of Spike2 software (Cambridge Electronic Design).

Single-cell stimulation experiments were performed at a mean depth reading of $5640 \pm$ $463 \mu \mathrm{m}$, which is likely an overestimate attributable to oblique penetrations and dimpling. All experimental procedures were performed according to Dutch and German guidelines on animal welfare under the supervision of local ethics committees.

Analysis. We restricted the analysis of behavioral responses to those single-cell stimulation and catch trials in which animals were considered attentive, as judged by their performance in microstimulation trials. Specifically, singlecell stimulation trials and catch trials were included if the animal responded in both the preceding and the succeeding microstimulation trial or if the animal responded in a microstimulation trial that immediately preceded or succeeded the respective trial. A cell was included in the dataset if at least five single-cell stimulation trials and five catch trials fulfilled this criterion. Reported single-cell stimulation and catch trial response rates refer to these included trials. AP rates/numbers, however, were calculated over all trials. Because animals were awake and displayed movements during the task, single-cell stimulation experiments were typically of short duration (median, $9 \mathrm{~min}$; maximum, $98 \mathrm{~min}$ ). An average of $22 \pm 18$ single-cell stimulation trials and $12 \pm 8$ catch trials were included per cell. All reported values are expressed as mean \pm SD if not indicated otherwise.

Histology and identification of stimulation sites. During the last few days of experiments with an animal, electrolytic lesions $(10 \mu \mathrm{A}, 10 \mathrm{~s}$, electrode tip negative) were made through the microstimulation electrode directly after single-cell stimulation experiments. After the final experiment, the animal was perfused transcardially with $0.1 \mathrm{M}$ PBS, followed by a $4 \%$ paraformaldehyde solution. The brain was removed, stored overnight in $4 \%$ paraformaldehyde solution, and either transferred to a $10 \%$ sucrose solution, embedded in gelatin, and sectioned frozen ( $80 \mu \mathrm{m}$ thick), or sectioned in $0.1 \mathrm{~m}$ phosphate buffer $(200 \mu \mathrm{m})$. Coronal slices were Nissl stained or stained for cytochrome oxidase (Wong-Riley, 1979) and examined for electrolytic lesions.

The following observations indicate that most of our experiments were performed in VPM. Seven of nine identified electrolytic lesions were located in VPM. The remaining two lesions were found in the ventral lateral thalamus and at the border of ventral lateral thalamus and the ventral posterior lateral nucleus, which relays information from body and paws to cortex (Fabri and Burton, 1991). To verify that we stimulated cells in whisker-related parts of the thalamus, we applied microstimulation at intensities $(8-15 \mu \mathrm{A})$ slightly higher than during psychophysical experiments through the nearby microstimulation electrode. Such stimulation evoked whisker movements at 20 of 21 tested sites. In some cells, we also assessed receptive field properties and observed a clear difference between principal and surround whisker responses as has been reported in VPM (Brecht and Sakmann, 2002a). Finally, neurons typically displayed two modes of AP firing characteristic for thalamic neurons: burst firing when the animal was inattentive, and tonic firing when the animal performed the task (Weyand et al., 2001; Woody et al., 2003). 
A

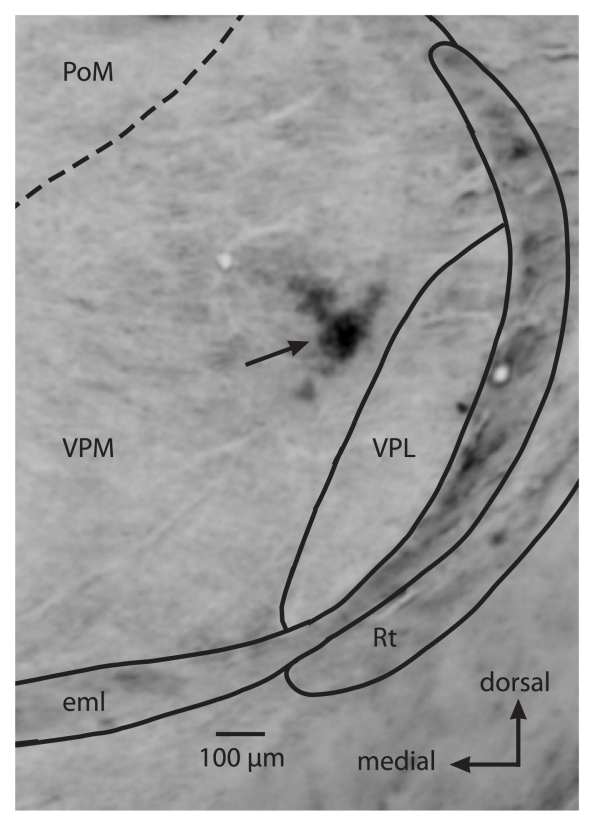

B

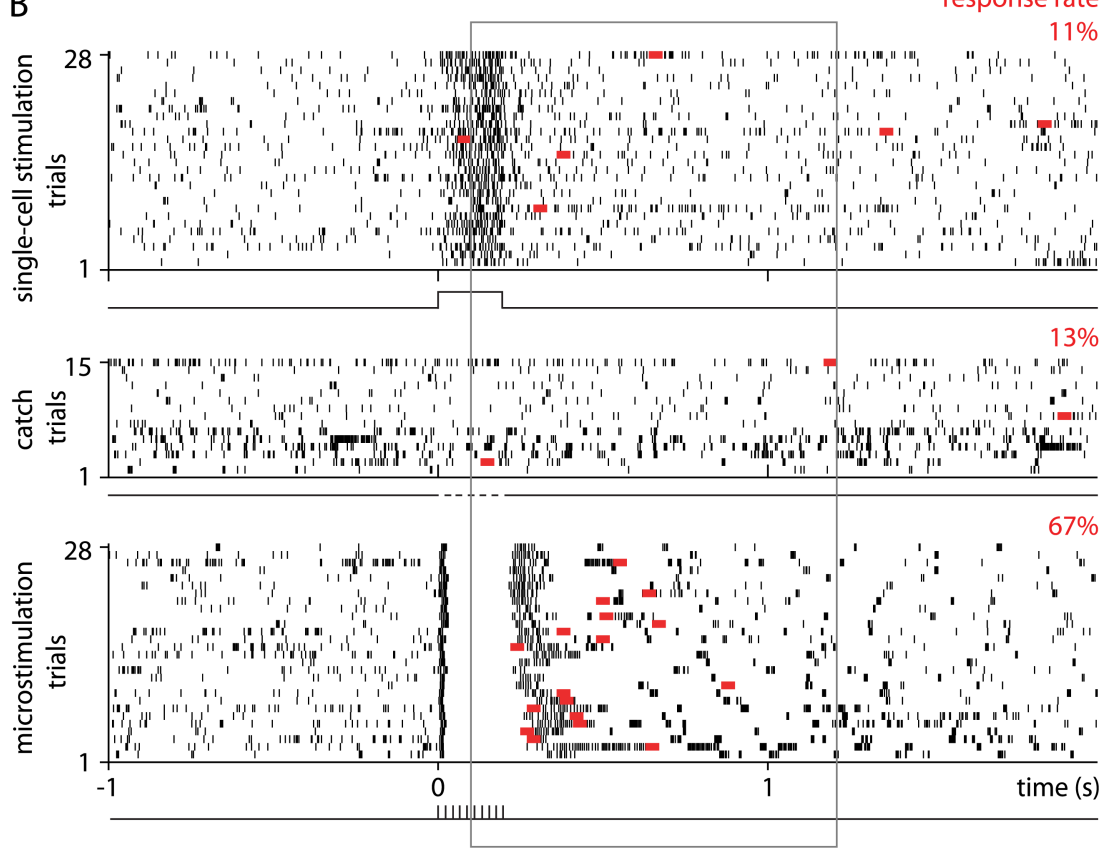

Figure 2. Behavioral responses during a single-cell stimulation experiment in VPM. A, The thalamic recording site, marked by an electrolytic lesion (arrow). Coronal section, $3.6 \mathrm{~mm}$ posterior to bregma. eml, External medullary lamina; PoM, posterior medial nucleus; Rt, reticular nucleus; VPL, ventral posterior lateral nucleus; VPM, ventral posterior medial nucleus. The dashed line indicates the putative border between VPM and PoM. B, Action potential raster plot (black tick marks) and first lick responses (red squares) during single-cell stimulation trials (top trace), catch trials (middle trace), and 28 randomly picked microstimulation trials (bottom trace). Stimulation currents were $16 \mathrm{nA}$ for single-cell stimulation and $6-7 \mu \mathrm{A}$ for microstimulation. Response rates (fraction of first licks in the response window) for the three different trial types are indicated above each raster plot.

\section{Results}

\section{Behavioral report of microstimulation in VPM}

Animals were first trained to respond with a tongue lick to a 200 ms train of microstimulation pulses applied to the VPM at random times (Fig. 1A). Animals quickly acquired this task, typically in the first session. Within a few days, current detection thresholds decreased from 5-70 $\mu \mathrm{A}$ in the first training session to $2-5$ $\mu \mathrm{A}$. These values are comparable with the lowest cortical microstimulation detection thresholds found in humans (Schmidt et al., 1996), monkeys (Bartlett and Doty, 1980; de Lafuente and Romo, 2005; Murphey and Maunsell, 2007), and rats (Butovas and Schwarz, 2007; Houweling and Brecht, 2008). Once animals responded consistently to microstimulation currents $\leq 5 \mu \mathrm{A}$, we started single-cell stimulation experiments.

\section{Rats do not report single-cell stimulation in VPM}

We closely approached a thalamic neuron nearby the microstimulation site with a glass pipette and evoked short $(200 \mathrm{~ms})$ trains of APs by juxtacellular stimulation (Houweling and Brecht, 2008). These single-cell stimulation trials were then randomly interleaved with microstimulation trials and catch trials without current injection (Fig. $1 B$ ), which were used to measure chance performance. Juxtacellular stimulation strongly modulated AP firing in VPM neurons (Fig. 1C,D). We observed on average $20.4 \pm 10.2 \mathrm{APs}$ during the $200 \mathrm{~ms}$ current injections, which corresponded to an eightfold increase over the average VPM spontaneous firing rate $(2.6 \pm 1.3 \mathrm{APs} / 200 \mathrm{~ms})$ and the addition of $17.8 \pm 10.1$ APs per stimulation trial.

A representative single-cell stimulation experiment on a VPM cell is displayed in Figure 2. The recording site was confirmed by an electrolytic lesion (Fig. 2A). Juxtacellular stimulation added on average $19.3 \pm 5.1$ APs in this cell during the current injection (Fig. 2B). Despite the strong AP modulation, response rates were similar for single-cell stimulation trials (hits, 11\%) and catch trials without stimulation (false positives, $13 \%$ ), whereas the animal responded to a large fraction $(67 \%)$ of microstimulation trials.

Statistical comparisons of single-cell stimulation and catch trial responses in individual cells have limited power given the typically small numbers of trials. We therefore compared hit rates and false-positive rates for our population of thalamic neurons $(n=36)$ (Fig. 3). This revealed that animals did not respond more often in single-cell stimulation trials (mean hit rate, 27.9\%) than in catch trials (mean false-positive rate, $27.9 \% ; p=0.507$, one-sided paired $t$ test).

Cells varied in the number of trials that could be recorded. However, effect size (hit rate - false-positive rate) did not depend on the number of trials (sum of single-cell stimulation and catch trials) $(r=0.002 ; p=0.989$, Spearman's rank correlation test), indicating that detection of single-cell stimulation did not improve with larger trial numbers.

To assess whether the strength of AP modulation affected the detectability of single-cell stimulation, we calculated a modulation factor for each cell (AP rate during stimulation divided by prestimulus AP rate). Effect size showed a nonsignificant association with modulation factor ( $r=-0.24 ; p=0.160$, Spearman's rank correlation test), indicating that single-cell stimulation remained undetectable in cells with relatively strong AP modulation.

Our previous results in barrel cortex (Houweling and Brecht, 2008) showed that single-cell stimulation effects were larger than average in animals that used a nonconservative response criterion. In our thalamic experiments, effect size showed no correlation with the overall response rate (pooled number of responses in single-cell stimulation trials and catch trials) $(r=0.011 ; p=$ 0.951 , Spearman's rank correlation test). Thus, single-cell stimu- 


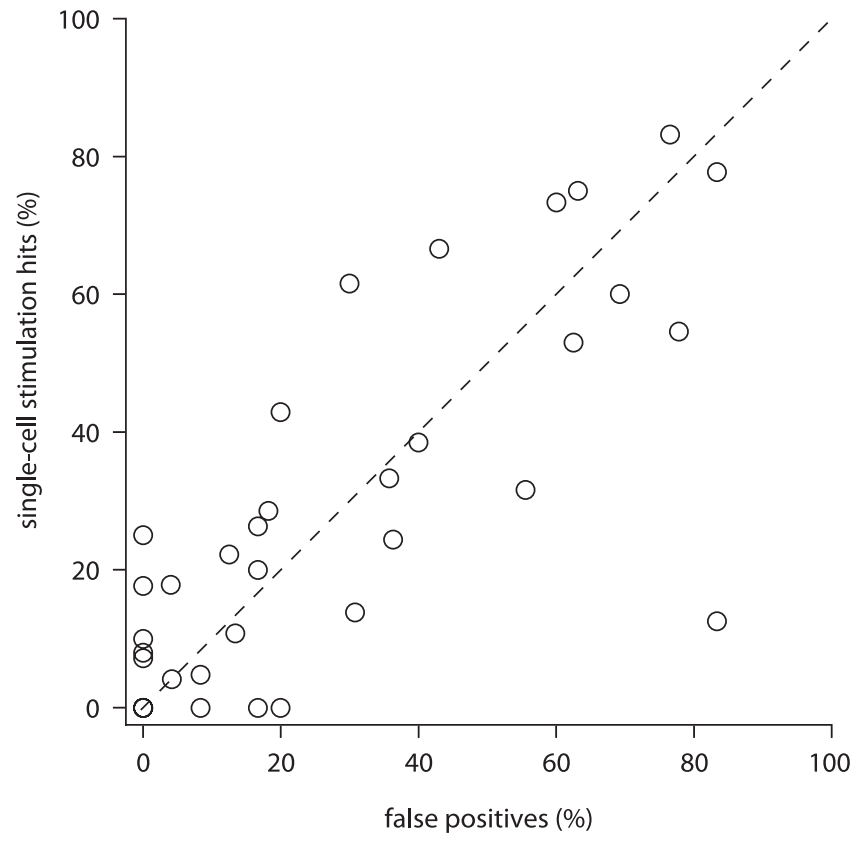

Figure 3. Action potential initiation in single neurons in whisker thalamus does not lead to a behaviorally detectable effect. Every circle represents the performance of an animal during one single-cell stimulation experiment. Response rates in single-cell stimulation trials (hits) are plotted versus response rates during catch trials (false positives) ( $n=36$ neurons, note 4 points coincide at the origin).

lation was undetectable regardless of the animal's response criterion.

\section{Juxtacellular stimulation activates single neurons in VPM}

The following observations indicate that juxtacellular stimulation evoked APs in single and not multiple neurons. (1) Juxtacellular labeling typically stains single neurons in VPM (Pinault and Deschênes, 1998). (2) We inspected each stimulation trial for the presence of AP waveforms other than that of the stimulated neuron. In 5 of 34 analyzed neurons, we observed a large secondary AP waveform $(>0.5 \mathrm{mV})$ during current injections. However, these large secondary events were rare and accounted only for $0.2 \pm 0.8 \%$ of the APs during current injections across all experiments (Fig. 4A). (3) In nine experiments, we also analyzed small secondary AP waveforms with amplitudes between 0.25 and 0.5 $\mathrm{mV}$ (Fig. $4 \mathrm{~B}$ ). AP rates during spontaneous activity and juxtacellular current injection were not significantly different for any of these small secondary units ( $p>0.05$, two-tailed binomial tests), indicating that small nearby units were not affected by juxtacellular stimulation.

\section{Discussion}

Microstimulation detection thresholds in whisker thalamus and cortex are comparable

The thalamus has recently become a focus of psychophysical microstimulation studies. In the monkey lateral geniculate nucleus, stimulation currents of $40 \mu \mathrm{A}$ were detected by the animal (Pezaris and Reid, 2007). In the ventral caudal nucleus of humans, Patel et al. (2006) reported microstimulation detection thresholds as low as $5 \mu \mathrm{A}$. In our study, rats learned to report microstimulation in VPM at currents of 2-5 $\mu \mathrm{A}$. The similarity of microstimulation detection thresholds in VPM with those in rat barrel cortex (Butovas and Schwarz, 2007; Houweling and Brecht, 2008) is somewhat surprising given the large differences in neural circuitry and numbers of neurons devoted to single whiskers.

\section{Animals do not report action potentials in single thalamic cells}

In contrast with our recent single-cell stimulation experiments in rat barrel cortex (Houweling and Brecht, 2008), we show here that stimulation of single thalamic neurons does not lead to a behaviorally reportable effect, although experimental conditions were virtually identical. In both studies, microstimulation and single-cell stimulation electrode tips were close $(<100 \mu \mathrm{m})$, and microstimulation currents were similar (thalamus, $5.4 \pm 1.5 \mu \mathrm{A}$; cortex, $5.0 \pm 1.6 \mu \mathrm{A}$ ), as were single-cell stimulation currents (thalamus, $14.5 \pm 7.8 \mathrm{nA}$; cortex, $12.6 \pm 7.8 \mathrm{nA}$ ) and microstimulation response rates (thalamus, $87 \pm 17 \%$; cortex, $75 \pm$ $17 \%)$. We note, however, that a direct statistical comparison of the single-cell stimulation effects in cortex versus thalamus leads to a nonsignificant difference ( $p=0.126$, two-sided unpaired $t$ test). This is not surprising given the low power of this statistical test ( $\beta=0.35$, assuming no behavioral effect of stimulation in VPM), which is attributable to the small average effect size $(\sim 5 \%)$ in cortex and the relatively small number of thalamic cells and trials.

There is of course a possibility that we missed a real but small single-cell stimulation effect in VPM attributable to the finite sample size or heterogeneities in the cell population. Recent evidence suggests the existence of two parallel pathways in VPM (Pierret et al., 2000) that convey functionally distinct sensory signals (Yu et al., 2006).

\section{Why is single-cell stimulation in whisker thalamus undetectable?}

Electrical stimulation of single tactile afferents from the hand elicits sensations of pressure, touch, vibration, or tickle in humans (Vallbo et al., 1984). Thus, given the detectability of singlecell activity both upstream and downstream of somatosensory thalamus, it is quite unexpected that the animal does not detect increased AP activity in single VPM cells. Moreover, the fact that whiskers are represented by fewer neurons in a thalamic barreloid than in the corresponding cortical barrel column argues that single VPM cells are at least as informative to the brain as single cortical cells. Detection of single-cell stimulation in barrel cortex presumably requires activation of neurons downstream (secondary somatosensory cortex and perhaps frontal lobe), either directly by the stimulated neuron or indirectly through the transsynaptic activation of other neurons in the barrel column. One possible explanation for the lack of single-cell stimulation effects in VPM involves differences in the organization of local neural circuits. Pyramidal cells in barrel cortex are densely interconnected (Feldmeyer et al., 1999; Lübke et al., 2000), which may allow the stimulated cortical neuron to activate surrounding neurons. In contrast, VPM neurons lack local recurrent excitatory connections and therefore a means for direct local amplification. Another possibility is that thalamocortical synapses are too weak and depressed for a single thalamic neuron to evoke downstream spiking. Studies in cats (Alonso et al., 1996) and rats (Pinto et al., 2000; Temereanca and Simons, 2003) suggest that sensory input should drive a substantial number of thalamic neurons in synchrony to transfer sensory information to cortex. Bruno and Sakmann (2006) estimated that a minimum of 30 VPM thalamic neurons account for the subthreshold response in layer 4 neurons of barrel cortex to a strong sensory stimulus $\left(5.7^{\circ}\right.$ whisker deflection at $570^{\circ} / \mathrm{s}$ ), whereas Liu et al. (2007) estimated that $\sim 18$ syn- 
chronously active cells in rat auditory thalamus saturate the neural response in cortex. A third possible explanation for the difference in single-cell stimulation effects between thalamus and cortex relates to the relatively high spontaneous firing rates in VPM. Although we added on average more APs in whisker thalamic neurons $(17.8 \pm 10.1)$ than in barrel cortical neurons $(13.6 \pm 6.3$ ) (Houweling and Brecht, 2008), spontaneous firing rates in thalamic neurons were also higher and the relative modulation of activity was therefore stronger in cortical cells (factor of 25) than in thalamic cells (factor of 8 ).

Overall, our findings suggest that sensory encoding is less sparse in VPM thalamus than at other stages of the sensorimotor loop. Thus, the "sensory weights" of spikes in thalamus seem to be smaller than those in cortex.

\section{References}

Afraz SR, Kiani R, Esteky H (2006) Microstimulation of inferotemporal cortex influences face categorization. Nature 442:692-695.

Alonso JM, Usrey WM, Reid RC (1996) Precisely correlated firing in cells of the lateral geniculate nucleus. Nature 383:815-819.

Bartlett JR, Doty RW (1980) An exploration of the ability of macaques to detect microstimulation of striate cortex. Acta Neurobiol Exp (Wars) 40:713-727.

Brecht M, Sakmann B (2002a) Whisker maps of neuronal subclasses of the rat ventral posterior medial thalamus, identified by whole-cell voltage recording and morphological reconstruction. J Physiol 538:495-515.

Brecht M, Sakmann B (2002b) Dynamic representation of whisker deflection by synaptic potentials in spiny stellate and pyramidal cells in the barrels and septa of layer 4 rat somatosensory cortex. J Physiol 543:49-70.

Bruno RM, Sakmann B (2006) Cortex is driven by weak but synchronously active thalamocortical synapses. Science 312:1622-1627.

Butovas S, Schwarz C (2007) Detection psychophysics of intracortical microstimulation in rat primary somatosensory cortex. Eur J Neurosci 25:2161-2169.

Castro-Alamancos MA (2004) Dynamics of sensory thalamocortical synaptic networks during information processing states. Prog Neurobiol 74:213-247.

de Lafuente V, Romo R (2005) Neuronal correlates of subjective sensory experience. Nat Neurosci 8:1698-1703.

de Lafuente V, Romo R (2006) Neural correlate of subjective sensory experience gradually builds up across cortical areas. Proc Natl Acad Sci U S A 103:14266-14271.

Erzurumlu RS, Bates CA, Killackey HP (1980) Differential organization of thalamic projection cells in the brain stem trigeminal complex of the rat. Brain Res 198:427-433.

Fabri M, Burton H (1991) Topography of connections between primary somatosensory cortex and posterior complex in rat: a multiple fluorescent tracer study. Brain Res 538:351-357.

Feldmeyer D, Egger V, Lubke J, Sakmann B (1999) Reliable synaptic connections between pairs of excitatory layer 4 neurones within a single "barrel" of developing rat somatosensory cortex. J Physiol 521:169-190.

Haidarliu S, Ahissar E (2001) Size gradients of barreloids in the rat thalamus. J Comp Neurol 429:372-387.

Houweling AR, Brecht M (2008) Behavioural report of single neuron stimulation in somatosensory cortex. Nature 451:65-68.

Huber D, Petreanu L, Ghitani N, Ranade S, Hromádka T, Mainen Z, Svoboda
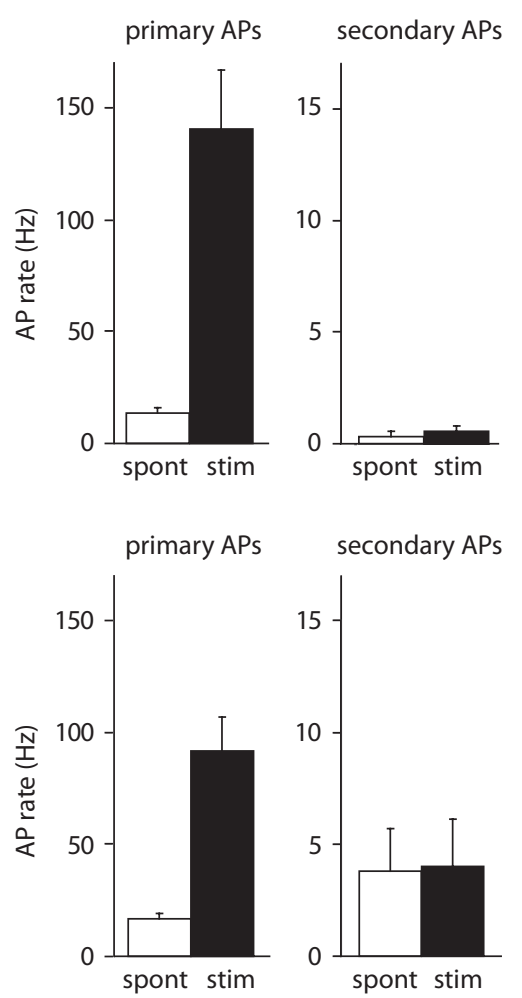

spont stim
$24 \mathrm{nA}$

spont stim

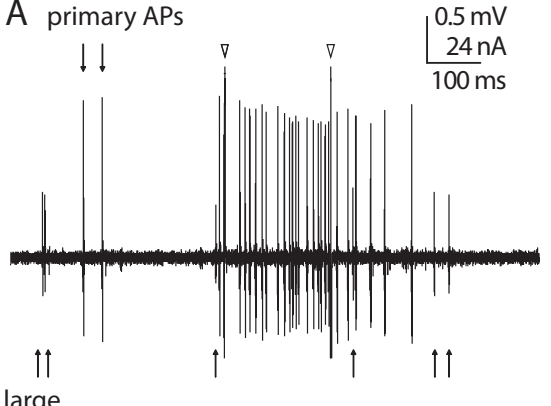

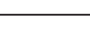

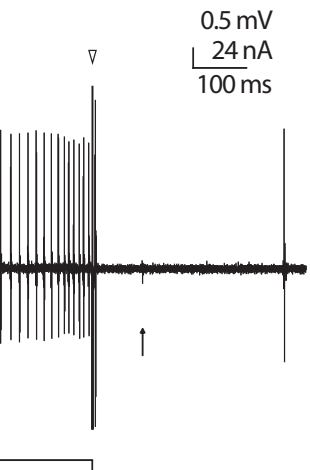

Large secondary action potentials are rare and small action potentials are not modulated by juxtacellular stimulation. experiments, large ( $>0.5 \mathrm{mV}$ ) secondary APs were observed in addition to the APs of the primary neuron that 9). Error bars indicate the SEM. Note the different scales. $\boldsymbol{B}$, Left, In all experiments, small $(0.25-0.5$ APs were found in addition to those of the primary neuron. Right, In nine experiments, we were able to quantify the pontaneous and evoked firing rates of the small secondary APs.

K (2008) Sparse optical microstimulation in barrel cortex drives learned behaviour in freely moving mice. Nature 451:61-64.

Jones EG, Diamond IT (1995) The barrel cortex of rodents. New York: Plenum.

Land PW, Buffer SA Jr, Yaskosky JD (1995) Barreloids in adult rat thalamus: three-dimensional architecture and relationship to somatosensory cortical barrels. J Comp Neurol 355:573-588.

Liu BH, Wu GK, Arbuckle R, Tao HW, Zhang LI (2007) Defining cortical frequency tuning with recurrent excitatory circuitry. Nat Neurosci 10:1594-1600.

Lübke J, Egger V, Sakmann B, Feldmeyer D (2000) Columnar organization of dendrites and axons of single and synaptically coupled excitatory spiny neurons in layer 4 of the rat barrel cortex. J Neurosci 20:5300-5311.

Lund RD, Webster KE (1967) Thalamic afferents from the spinal cord and trigeminal nuclei. An experimental anatomical study in the rat. J Comp Neurol 130:313-328.

Ma PM (1991) The barrelettes: architectonic vibrissal representations in the brainstem trigeminal complex of the mouse. I. Normal structural organization. J Comp Neurol 309:161-199.

Murasugi CM, Salzman CD, Newsome WT (1993) Microstimulation in visual area MT: effects of varying pulse amplitude and frequency. J Neurosci 13:1719-1729.

Murphey DK, Maunsell JH (2007) Behavioral detection of electrical microstimulation in different cortical visual areas. Curr Biol 17:862-867.

Nicolelis MA, Fanselow EE (2002) Thalamocortical [correction of Thalamcortical] optimization of tactile processing according to behavioral state. Nat Neurosci 5:517-523.

Patel S, Ohara S, Dougherty PM, Gracely RH, Lenz FA (2006) Psychophysical elements of place and modality specificity in the thalamic somatic sensory nucleus (ventral caudal, vc) of awake humans. J Neurophysiol 95:646-659.

Pezaris JS, Reid RC (2007) Demonstration of artificial visual percepts gen- 
erated through thalamic microstimulation. Proc Natl Acad Sci U S A 104:7670-7675.

Pierret T, Lavallée P, Deschênes M (2000) Parallel streams for the relay of vibrissal information through thalamic barreloids. J Neurosci 20:7455-7462.

Pinault D, Deschênes M (1998) Anatomical evidence for a mechanism of lateral inhibition in the rat thalamus. Eur J Neurosci 10:3462-3469.

Pinto DJ, Brumberg JC, Simons DJ (2000) Circuit dynamics and coding strategies in rodent somatosensory cortex. J Neurophysiol 83:1158-1166.

Romo R, Hernández A, Zainos A, Salinas E (1998) Somatosensory discrimination based on cortical microstimulation. Nature 392:387-390.

Salzman CD, Britten KH, Newsome WT (1990) Cortical microstimulation influences perceptual judgements of motion direction. Nature 346:174-177.

Schmidt EM, Bak MJ, Hambrecht FT, Kufta CV, O'Rourke DK, Vallabhanath P (1996) Feasibility of a visual prosthesis for the blind based on intracortical microstimulation of the visual cortex. Brain 119:507-522.

Simons DJ, Carvell GE (1989) Thalamocortical response transformation in the rat vibrissa/barrel system. J Neurophysiol 61:311-330.

Tehovnik EJ (1996) Electrical stimulation of neural tissue to evoke behavioral responses. J Neurosci Methods 65:1-17.

Temereanca S, Simons DJ (2003) Local field potentials and the encoding of whisker deflections by population firing synchrony in thalamic barreloids. J Neurophysiol 89:2137-2145.

Vallbo AB, Olsson KA, Westberg KG, Clark FJ (1984) Microstimulation of single tactile afferents from the human hand. Sensory attributes related to unit type and properties of receptive fields. Brain 107:727-749.

Van der Loos H (1976) Barreloids in the mouse somatosensory thalamus. Neurosci Lett 2:1-6.

Weyand TG, Boudreaux M, Guido W (2001) Burst and tonic response modes in thalamic neurons during sleep and wakefulness. J Neurophysiol 85:1107-1118.

Wong-Riley M (1979) Changes in the visual system of monocularly sutured or enucleated cats demonstrable with cytochrome oxidase histochemistry. Brain Res 171:11-28.

Woody CD, Gruen E, Wang XF (2003) Electrical properties affecting discharge of units of the mid and posterolateral thalamus of conscious cats. Neuroscience 122:531-539.

Woolsey TA, Van der Loos H (1970) The structural organization of layer IV in the somatosensory region (SI) of mouse cerebral cortex. The description of a cortical field composed of discrete cytoarchitectonic units. Brain Res 17:205-242.

Yu C, Derdikman D, Haidarliu S, Ahissar E (2006) Parallel thalamic pathways for whisking and touch signals in the rat. PLoS Biol 4:e124. 